\title{
El ataúd de cristal. Ser o no ser Blancanieves
}

\author{
Christophe DE VAREILLES ${ }^{1}$ \\ christophedevareilles@yahoo.fr
}

Recibido: 8-6-15

Aceptado: $30-9-15$

\section{Resumen}

Cuando hablamos de una vida acabada, no necesariamente estamos en el territorio de la muerte física. Proponemos extender esta idea para incluir tanto etapas que concluyen, como también aquellas existencias que están de alguna manera fuera de la vida, fuera del circuito de la normalidad. Es decir excluidas del campo de la "vida laboral", de la utilidad y operatividad, y que de algún modo se sitúan en esa otra gran zona que podríamos denominar como la basura de la vida. Como aconteciendo en un lapsus, en un sin sentido, ni viva ni muerta, pero en una vida acabada... situadas en el ataúd de cristal donde los enanos aislaron a Blanca Nieves. Vidas acabadas, consideradas absurdas, obsoletas, vidas que estorban, carentes de importancia, desechables, intocables con los que ya no sabemos como relacionarnos. Otras "muertes “, que comienzan muy temprano en la calle o en instituciones. Gradualmente se hizo claro para mí que los talleres acogiendo a personas sin hogar, marginadas por las adicciones, estigmatizadas por la enfermedad, se enmarcan mucho más en los cuidados paliativos que en la "psicoterapia".

Palabras clave: Proximidad profesional; acompañamiento social; territorios del negativo; exclusión; mirada humanista del cuidado.

\section{The glass coffin, to be or no to be Snow White}

\begin{abstract}
We can widen the notion of « end of life » by including lives that are out of the race/circuit, excluded from "active life" and economic usefulness, and which entered this other major area of life we usually consider as the garbage of existence. We could compare this space to the glass coffin where the dwarves secluded Snow White, neither alive nor dead, but in end of life. This "end of life" starts very early in institutions or for those who live in the streets. Our society reinstated, without noticing, a caste of "untouchables" with whom we don't know anymore how to relate. Accompaniment of the end of life actually appears closely bound to accompaniment of these lives finished, considered as "obsoletes", expendable, disturbing... It gradually appeared to me that my workshops with homeless people or people deeply damaged by addictions were closer to palliative care than to "psychotherapy".
\end{abstract}

Key words: Professional proximity; social care; territory of the negative; exclusion; humanist approach of care. 


\section{Sumario}

Introducción; Pronto-muertos o todavía vivos; Límites del acompañamiento; Acompañar vidas acabadas; Exclusiones de la vida; Paliativos ampliados; Un enfoque centrado en la persona; El ataúd de cristal; El acompañamiento recíproco; Conclusiones; Bibliografía.

\section{Introducción}

El fin de una vida no es una realidad clara y precisa. No se puede definir o medir objetivamente. ¿En qué momento podríamos decir que la vida se encamina a su fin, o que comienza a acabar? ¿Cuántos días, semanas o meses dura este ir concluyendo la vida? ¿Es acaso posible distinguir un período que podría llamarse "el fin de vida" y diferenciarlo de la "vida" en sí misma? ¿Y qué criterios definen el umbral de la una a la otra? Cada vida acaba de una manera tan singular: a veces tan de repente que no se habrá podido planear nada, y otras veces en un tiempo tan largo, tan infinitamente lento que parece disolverse en una duración sin límite.

Sin nunca haber trabajado en un servicio de cuidados paliativos, me encontré regularmente con personas cuyas vidas acabaron, a veces sin que nadie sepa nada, en los diferentes talleres que acompañé: talleres de pintura en el hospital, acogiendo enfermos de sida, talleres para personas dependientes atendidas en un servicio de adicción/alcoholismo o talleres acogiendo personas sin techo y en situación de precariedad ... Y poco a poco, tomé conciencia de que la vida se puede considerar como terminada incluso mucho antes de que sea tiempo de morir. Algunas vidas se vuelcan en una forma de des-compromiso de sí mismo o del mundo, en una retirada que ya forma parte del fin. A menudo nos codeamos con largos finales de vida, con vidas acabadas desde ya hace tiempo, que nunca acaban de acabar, estando allí sin verdaderamente estar, o vidas que nos dan la impresión de estar ya muertas. A veces tratamos de acompañarlas. Incluso algunas personas, que nacen con ciertas discapacidades, desde el primer momento pueden ser consideradas como vidas ya finitas.

Por lo general, nos representamos la muerte como un punto final, donde la respiración nos abandona, donde el corazón deja de latir, donde el cuerpo empieza a enfriarse: pero esto es sólo el final de la vida biológica. Nuestra vida no puede reducirse a la de nuestros órganos y su funcionamiento. No somos sólo nuestro cuerpo. La muerte, en nuestras vidas, empieza antes de lo que pensamos, mucho antes de que nosotros nos demos cuenta.

La vida laboral puede marchitarse, la vida social romperse, la vida relacional ser arrinconada, la vida psíquica interrumpida de repente o deshecha lentamente. Y en lugar de hablar sobre el fin de vida en su conjunto, podríamos hablar de esta multiplicidad de experiencias donde la vida se reduce, se agota, se fragmenta, se deja como en suspenso, en margen o en retirada, donde ella se ahoga, silenciada, ausente, rota...

\section{Pronto-muertos o todavía-vivos}

Jeanne y Eric acudieron al taller durante casi dos años. 
Recuerdo esta extraña petición hecha un día por Jeanne: "Estoy enferma, no es curable, se trata de un cáncer. ¿Puedo venir al taller con mi marido? “

Eric era un hombre modesto, recatado, muy interior. Hablaba poco. Jeanne hablaba mucho más, siempre tenía la necesidad de que se ocuparan de ella, pidiendo un montón de pequeños consejos superficiales, que le diesen una opinión sobre todo lo que hacía, cada decisión que ella tomaba o dudaba en tomar por su pintura, si era mejor con acuarelas o lápiz, empezar otra cosa o terminar un trabajo iniciado. Ella pedía constante atención: ¿Este es el color correcto? ¿Se parece al modelo? ¿Crees que está acabado? A veces era un poco agotador e invasivo, y más de una vez, lo que me entraba ganas de decirle era: "Así que cállate un poco y dibuja..."

Y luego poco a poco descubrimos cómo lo cotidiano de Jeanne y Eric era rudo. Cómo era doloroso para ella soportar su silencio, y para él soportar la charla de ella, sus preguntas un poco infantiles, y la expresión difusa de su angustia a través de estas demandas incesantes. Y descubrimos lo solos que estaban. Nadie a su alrededor, ni un amigo con quien hablar, compartir cosas. De hecho, el cáncer, la proximidad de la muerte, les separaron rápidamente de cualquier vida social, los amigos dejaron de venir, y los que vinieron no vieron nada más que la enfermedad y sus propios miedos. El vacío se hizo en unos pocos meses. Les miraron como muertos con indulto, ya fuera de la vida, les habían sacado del mundo de los vivos. Cada mirada, en silencio, parecía sugerir en términos velados: "todavía no está muerta..."

Lo que Jeanne y Eric vinieron a pedir al taller era la oportunidad de ser vistos de manera diferente. No tenían ganas de hablar de la muerte, ni de mirar la vida como ya cerrada, de que ahora solo faltaría hacer un balance, como si de una declaración de impuestos se tratara cuando termina el año fiscal o de pagar la cuenta cuando se acaban las compras. No tenían ganas de ser recibidos como un problema a resolver, o para lecciones de sabiduría o consejos de cómo vivir su fin de vida con dignidad o ejemplaridad. Solo querían ser esperados simplemente como el asiduo cliente de un café, o los viejos amigos, presencias habituales que se acogen familiarmente, como una parte más de la realidad, sin que nadie trate de cambiarlos, espiritualizarlos, ayudarlos. Solo deseaban estar ahí.

No vinieron al taller a pedir un tipo específico de ayuda, ni un cuidado especial de ellos, más bien era como una petición de asilo. Pidieron pertenecer.

En cuanto se sentó, Eric se sumergió en su dibujo como en un sueño, se escapó a otro mundo libre de los hábitos cotidianos y su peso. Durante varios meses, hizo una larga serie de rostros, que eligió en revistas y copió con lápiz en blanco y negro. Todos sus rostros, uno tras otro, como un entorno familiar, silencioso como él. A falta de estar rodeado de presencias amistosas, se rodeó de representaciones de estas presencias. Derecho de rodearse de silencios, testigos comprensivos, acogedores, sin necesidad de hablar.

Él tuvo que darse a sí mismo el derecho de quedarse silencioso sin tener que hacer un esfuerzo. Ella, el derecho de ser un poco pesada, con sus llamadas agotadoras, el derecho también que le pidamos que se calle como a cualquier persona normal. Solo pidió el derecho a venir, sentarse con nosotros, sentirse perdida, decir y repetir su necesidad de que estemos con ella en la soledad de sus decisiones irrisorias. El 
derecho de solicitar una y otra vez que se le diga qué hacer y cómo hacerlo, y de escucharnos contestar que no sabemos y que no es muy importante...

Ganas de ser aceptados tal como son, como los demás, de poder relacionarse con normalidad.

Ellos sabían que ella no tendría muchos años de vida, quizás uno o dos, o tres, quizás menos. ¿Qué debemos hacer de los días que quedan por vivir juntos cuando sabemos que son limitados, pero quizás muchos? ¿Más allá que arreglarse con respecto al otro, a sí mismo, al mundo, cómo llenar todo ese tiempo que se estira sin proyecto ni objeto? ¿Y cuando el fin de vida, siempre esperado, nunca alcanzado, no deja de no acercarse? Esperamos en el andén del tren que sale, y el tren no sale. Jeanne, con cada pintura, se preguntaba si era realmente útil empezarla o acabarla.

\section{Dos años en el andén. ¿Que decimos?}

La vida cotidiana, los horarios, las cosas superficiales, conversaciones ordinarias sin particular interés, las rutinas de la existencia, molestias normales y las cosas aburridas corrientes. No es porque no nos queda mucho tiempo, que la vida deba ser extraordinaria en cada momento. A menudo idealizamos el instante de nuestra muerte, como si fuese un umbral con una tarea en particular, la de recibir lo que se nos debe, de rendir cuentas, de revelar lo que estaba oculto, de escuchar lo que no nos dijeron, ... Un momento de iniciación a un misterio inaccesible a los vivos. Pero nada. La vida continúa de la misma manera, mi muerte inminente no cambia el mundo. Lo esencial del tiempo del fin no está del lado de la terminación, sino de la continuación. Es todavía vida, con menos deseo.

Para nosotros, lo difícil es acompañar a los vivos, en lugar de pre-enterrar a unos seres pronto-muertos. Sólo vivir este tiempo de la espera, vacío de cualquier proyecto, sin ilusión de un objetivo a lograr. Tiempo presente

\section{Límite Del Acompañamento}

Eric y Jeanne vinieron dos años. Formaban parte del grupo que, como a los antiguos, no se les discute su lugar. Excepto cuando estaban ausentes. Un día me advirtieron de que ya no podían venir al taller debido al transporte: Jeanne tuvo un accidente y el coche fue inutilizable. Me pregunté sobre el límite de mi papel: ¿podríamos ofrecernos para ir a buscarles a su casa o debería simplemente tomar nota de esta nueva dificultad para ellos?

Primero le pregunté a otra participante del taller si era posible para ella recogerlos en su coche, y rechazó con el pretexto de la distancia. Fue imposible explicar más. Creo que en realidad no tenía miedo a la distancia sino a la proximidad que este servicio podría suponer. No hay duda de que tenía demasiado miedo a verse alistada al servicio de una persona enferma, y quizá sentirse contra su voluntad comprometida en una obligación moral de la que sería imposible escapar una vez hubiera aceptado. Era una responsabilidad demasiado angustiosa, demasiado pesada para ella sola, y sin la protección suficiente del grupo o de la institución. Tal vez habría podido aceptar estos riesgos si hubiera estado acompañada, pero no encontré a nadie para que fuesen dos. Entonces le pregunté a una estudiante en prácticas, María Paz Obispo, si podía 
hacer el viaje, y ella estuvo de acuerdo. Por lo tanto, propusimos a Eric y Jeanne que les llamasen por teléfono antes de cada sesión, para que se sintieran libres de venir o no según la salud o las fuerzas de Jeanne.

Este es el testimonio aportado por Marie-Paz que realizó el acompañamiento en esta situación muy específica, durante su período de prácticas en arteterapia.

Preguntas que me fui planteando en esta circunstancia: asegurar el transporte en coche para permitir a estas persones su asistencia al taller: ¿en qué medida se trataba efectivamente de un acompañamiento? ¿En qué medida se enmarcaba esta actividad en lo que es un acompañamiento arteterapéutico? ¿Estaba realmente preparada para ello? ¿Qué sentido esta experiencia podía tener para ellos y para mí?

\section{Algunas reflexiones:}

- Adaptarme a una situación inesperada y desconcertante en el contexto de arteterapia

- Ampliar mi concepto de lo que es el acompañamiento de arteterapia

- Dejar que se exprese mi humanidad

- Ser capaz de aprehender las expectativas y demandas de esta pareja en su asistencia al taller

- Aceptar la emergencia de una huella de mi oscuridad: no tener que lamentar nada tras la muerte de Jeanne. ¿Por y para quién acepto ocuparme de los traslados (casa-taller/ taller-casa)? ¿por qué este compromiso?

- Encontrarme en la tesitura de experimentar un proceso en el que aporto una contribución y ampliando así el marco que suele requerir este tipo de acompañamiento.

- Asumir todo aquello que esta situación pudiera despertar en mí ante la proximidad del término de la vida y de la muerte.

- Evitar no contribuir al sentimiento de aislamiento al que estaban enfrentados

- Respetar la importancia que tiene para la pareja el vivir este tiempo de taller como un paréntesis en su cotidianidad.

\section{Tres etapas de acompañamiento:}

1. Todas las semanas confirmo por teléfono la cita para el transporte y siempre manifiestan un inmenso agradecimiento por el apoyo que les brindo. Su reacción me conmueve a mi también. Me doy cuenta de lo mucho que para ellos significa esta cita semanal.

2. Durante el transporte: el tiempo que pasamos juntos en el espacio reducido de un coche se convierte en un momento de intimidad compartida; también profundizamos en los intercambios en torno a los miedos, los proyectos y la enfermedad, abordamos igualmente los temas más sencillos de la vida cotidiana. Respetamos los silencios. Se establece un vínculo sutil entre nosotros; me esmero en prestar atención al lugar que me corresponde, que sea lo más justo posible para no ser intrusiva; no caer en una pseudo-liviandad que podría ser signo de huida.

Me doy cuenta de que poco a poco este espacio se está convirtiendo en un ámbito de confianza y de que constituye una etapa que prepara el poder compartir en otro 
nivel el acompañamiento de la producción pictórica de Jeanne en el taller. Es un "antes" que permite un "después" más fluido, más auténtico y de confianza.

3. En el taller: estoy disponible para Jeanne. Se trata de "estar con" respetando a la vez la autonomía de Jeanne, estar al lado de y no "por delante de". Soy consciente de que estoy acompañando a una persona en su vivencia. Ceñirme a una escucha y a una disponibilidad sutiles, estar más alerta aún, si cabe, que si se tratara de otra persona y al mismo tiempo valorar la evolución de la enfermedad incapacitante, en el plano físico y psicológico. Todo ello se desarrolla en un marco muy especifico que exige un reajuste en cada sesión. Lo que ella consigue en una sesión puede no ser posible en otra, pero Jeanne tiene la férrea voluntad de llevar a término su producción, aun con momentos de cansancio y de desaliento cuando no se siente capaz de hacer determinados gestos (recortes, collage...).

Permanezco muy atenta a un exceso de implicación por mi parte que me alejaría del lugar justo que me corresponde. La escucha y la comunicación no-verbal de Jeanne van adquiriendo más importancia en mi relación con ella.

Jeanne se sintió muy orgullosa de ver su cuadro terminado. Luego no volvió más al taller.

\section{Eric:}

Mi acompañamiento de Jeanne en el taller era una manera indirecta de acompañar también a Eric. Mientras se desarrollaba el taller, Eric podía centrarse en si mismo, abrirse y disfrutar con su propia capacidad creativa.

Se sentía aliviado de las frecuentes demandas de Jeanne.

A lo largo de este período he ido tejiendo un vínculo muy especifico con Eric aun no habiéndose expresado verbalmente como tal en el espacio taller. Creo haber percibido en esos momentos que él se metía en una burbuja protectora y me pasaba, momentáneamente, el testigo.

Mirando hacia atrás, nuestro lugar y nuestro trabajo habrían sido asumir el riesgo de mover los límites de lo que consideramos como "normal" en una actitud de acompañamiento "profesional". Lo que nos solicitaron, fue simplemente no escondernos mirando a otro lado. Incluirlos. ¿Qué límite poner a esta intimidad? No estábamos obligados a dar ese paso más allá, ir hasta su puerta, recogerlos en el coche. ¿Acercarse? Una forma de tomar la mano: a ella, en lo que la aislaba - y a él en ese lugar tan dificil de mantener, estar siempre cercano, y sentirse impotente... Eric y Jeanne necesitaban que supiéramos ajustar nuestra proximidad. Creciendo en la intimidad sin la intrusión. Con demasiada frecuencia, estamos hablando de la buena distancia profesional, como si la proximidad no pudiera ser otra cosa que un fallo. Pero la proximidad buena es, también, un 'saber-ser' esencial, una habilitad del acompañamiento.

\section{Un riesgo de vida}

Lo que quiero destacar es la forma en que fueron capaces de utilizar el taller para acercarse y compartir sus representaciones, lo que tenían que vivir juntos sin poder decirlo verbalmente ; cómo el taller fue un espacio abierto a lo incomunicable de su relación... Cómo estos tiempos, regulares y simples, también permitieron que la 
ternura y la delicadeza se produjeran de forma discreta y les envolvieran, sin que fuera necesariamente de una manera física; evocar la ternura que despertaron en nosotros, lo que nos invitaron a abrir dentro de nosotros...

Esto fue inventar un vínculo de vivos a vivos, en lugar de acompañar a una conclusión.

\section{Acompañar vidas acabadas}

En el taller de adictologia que hice de 2002 hasta 2014, acogimos a otras personas en fin de vida aún sin saberlo. Martine, Jacky, que se suicidaron, sin que lo pudiéramos anticipar. Martine estuvo durante diez años en el taller, conocimos sus cambios de humor, sus profundas fases de desaliento seguidas por un entusiasmo emocionante. Su relación con el taller tenía algo de la niñez. Podía reírse de sí misma, también podía decir su angustia, su ternura, refugiarse en el taller, y a veces violentamente cuestionar nuestro papel y desafiarnos duramente en nuestra responsabilidad como cuidadores. Fui tan ingenuo que creí que este lugar podía protegerla. Quizás lo hizo durante diez años. Su muerte nos hizo conscientes de esta dolorosa evidencia: el taller no protege de nada. El hospital no protege de nada. El acompañamiento no protege de nada. Y el acompañante tampoco. No es una garantía para sentirse mejor. El suicidio sigue siendo una posibilidad, una tentación, una amenaza. La violencia contra uno mismo viene de dentro de uno mismo, el taller no preserva a nadie. Martine no fue protegida, y fuimos remitidos a nuestra propia fragilidad, nuestras ilusiones de protección mágica. Varios de nosotros estuvimos muy desestabilizados. Todo el mundo se sentía muy vulnerable, y como Martine, en potencial fin de vida. ¿Desde cuándo el fin de vida de Martine había empezado ya? ¿Y la nuestra, desde cuándo se había puesto en marcha a nuestra espalda?

Dependiente del alcohol durante diez años, Jacky había recaído cuatro veces, odiaba haber caído de nuevo. Se odiaba a sí mismo por no ser capaz de tener éxito por sí solo. Odiaba su vida de la que quería escapar. Durante muchos años se había escapado con el alcohol y los deportes extremos, una especie de violencia que se imponía para sobresalir. Por fin salir de sí mismo, para empezar. Probablemente, el taller no era suficiente, demasiado lento. Necesidad de ir más rápido. Se dejó atropellar en la noche por un coche. Estoy seguro de que se enfrentó al choque esperando un renacimiento, un nuevo comienzo. Creo que su suicidio fue un gesto de ese orden: franquear un umbral para empezar a vivir.

El fin de vida de Jacky, Martine, no estuvo marcado por la enfermedad, les habíamos acompañado sin saber que sus vidas se acababan.

\section{Exclusiones de la vida}

En el taller que sigo animando con personas sin techo, Thierry, Patrice, como otros, forman parte de las personas que han muerto en la calle. Uno murió violentamente, el otro muy rápidamente a causa de una infección no tratada. Un día en el momento de la acogida, no los vimos volver, luego comprendimos que estaban muertos. Las personas sin hogar mueren más jóvenes que los otros. En Francia, entre 2008 y 2010, la edad media de muerte en la calle era de 49 años contra 77 años para la población 
general. La acumulación de trastornos físicos y psiquiátricos, el retraso de acceso a los cuidados, a lo que se suma, por una parte la frecuente violencia personal, facilitada por el alcohol y el consumo de drogas y, por otra, la precarización de los pacientes psíquicos sin seguimiento y sin enlace, separados de la comunidad de pertenencia, sin ningún tipo de control social. La falta de protección en los 'squats', cuevas, refugios improvisados, aparcamientos o plazas donde pasan las noches, y la lejanía de la posibilidad de apoyo, multiplican las probabilidades de muerte prematura, lejos del mundo de los vivos. Deriva lenta, el fin de vida puede simplemente empezar por la invisibilidad social ${ }^{2}$.

Thierry, Patrice, Martine, Jacky, Jeanne, Eric... Cada uno de estos encuentros me lleva a ampliar el concepto de una "vida acabada " para incluir en el también el de las vidas salidas del circuito, esas existencias excluidas del ámbito de la "vida activa", de la utilidad económica, de la vida pública, de la vida social, empujadas poco a poco hasta el límite de la humanidad, cada vez más lejos de una oportunidad de estar en relación, de ser vinculadas. Estas vidas que entraron en esta vasta zona de contorno ligeramente borroso que consideramos como la basura de la vida y nos horroriza. Esta zona donde los que entran ya no son consultados nunca más, sobre decisiones que directamente les afectan, desinformados, ignorados, no más considerados ni contabilizados. Tampoco visitados, ni percibidos desde hace mucho tiempo como una fuente de alegría a la que alguien puede acercarse. El país de la inexistencia.

Gente de la calle, inmigrantes sin papel, ilegales, refugiados, enfermos, personas con discapacidad, adultos colocados bajo tutela en contra de su voluntad, trabajadores precarios, desempleados, ancianos y viejos, personas y pequeños grupos de minorías aisladas "periferizadas", dejadas de lado, o que temen la integración, la huyen o la rechazan ... Es larga la lista de los que silenciosamente salen de escena y cuya desaparición social se consiente y se olvida, paralelamente al cuidado de que son objeto legalmente. Son vivos que ya hemos empezado a enterrar, cuya desaparición progresiva no solo es consentida y abdicada, sino también organizada e institucionalizada. Cruel ambigüedad de muchas instituciones que fueron concebidas para tratar y contener estas demasiado inquietantes realidades, y que se convierten en guetos bajo la apariencia de acogerlos. Estos mundos que el sociólogo Dominique Lhuilier (2011) nombra "territorios de lo negativo": cárceles, hospitales psiquiátricos, hogares de ancianos, centros de detención, centros sociales, por no mencionar las asociaciones de apoyo de proximidad ... zonas de retirada, refugios, espacios híbridos entre la integración y el rechazo - ni realmente en la sociedad, ni completamente fuera de ella, entre la tolerancia y la desaparición - ni en la vida, ni en la muerte: ni-ni ...

El rendimiento, la eficiencia, el crecimiento, el éxito, son ahora tan extensamente percibidos como las condiciones evidentes de la existencia social, que tendemos, a pesar nuestro, a considerar como "vidas acabadas" todas las vidas que no tienen utilidad más clara, ni función manifiesta, ni más proyectos, a veces, ni más voz ${ }^{3}$. Así que, sin tomar realmente conciencia de esto, o sin poderlo reconocer, nuestra sociedad sigue produciendo una casta de "intocables", todas aquellas personas con las que no sabemos cómo relacionarnos, que tratamos como residuos de la humanidad y que se desvanecen poco a poco y desaparecen de nuestro campo de visión... Personas 
desplazadas lejos del espacio público, cuya invisibilidad es producida y mantenida por la mirada del grupo (Emmanuelli, 2009). Cuando Blanca Nieves cae al suelo por tercera vez, ni viva ni muerta, los siete enanitos la colocan en un ataúd de cristal. Este ataúd separa del mundo lo que encierra, lo aísla de cualquier relación y disminuye mucho sus posibilidades de reinserción. ¿Cómo no pensar en el destino de Blanca Nieves ante estas nuevas arquitecturas frías de metal y vidrio lisos que ahora sirven de residencias de ancianos y centros técnicos hospitalarios cercanos a carreteras de circunvalación y lejos del centro de las ciudades?

Fin de vida, borde del mundo. En alcohologia/adictologia, a menudo me codeé con gente con vidas desembragadas, gente un poco desorientada, cuyas existencias estaban fuera de los carriles de la normalidad y cuyo resto por vivir era una especie de "pre-fin de vida" sin que por ello su muerte fuera inminente. Su pregunta podía formularse de la siguiente manera: ¿cómo podría prolongarse una vida ya muerta, rota, destruida e irrecuperable?

Y poco a poco, me di cuenta de las muchas correspondencias existentes entre el acompañamiento de fin de vida y el de aquellas "vidas obsoletas", colectivamente vergonzosas, socialmente desenganchadas. Entonces parecía que mis talleres con personas muy dañadas por adicciones o sin hogar, se acercaban más a los cuidados paliativos que a una psicoterapia...

\section{Paliativos ampliados}

Aunque los cuidados paliativos no sean mi área de trabajo, estoy conmovido por la mirada sobre la persona y el sentido de acompañamiento que han desarrollado, que creo son relevantes en muchas otras situaciones de asistencia a la persona: en arteterapia, en coaching o bien en los oficios de apoyo social y médico. Aunque mi conocimiento sea parcial y subjetivo, tomaría el riesgo de aislar tres características de los cuidados paliativos para transponerlas a otros campos del acompañamiento, esperando verdaderamente que me perdonen estas simplificaciones y aproximaciones.

Así propongo tres puntos a seguir:

- dar paso a la autonomía del paciente y a su palabra

- rechazo de la excesiva obstinación terapéutica

- rechazo de acelerar la muerte

- Aplicado al contexto del apoyo social, del desempleo o de la reinserción, pueden formularse de la siguiente manera:

- reconocer a la persona aislada, dirigirse a ella como a un interlocutor de pleno derecho, darle un espacio de visibilidad, ponerse a su escucha

- prudencia sobre el realismo del proyecto de inserción (sin obstinación por reinsertar)

- prioridad al mantenimiento del vínculo relacional (evitar una mayor exclusión) y la posibilidad de una intimidad de sujeto a sujeto ${ }^{4}$.

Por ejemplo, aceptar que el acceso al empleo no siempre es un objetivo adecuado, que la apuesta está también a veces en acompañar a la pérdida de autonomía y la descrecencia o la dependencia, sin perder las otras dimensiones de la persona, su 
capacidad de emocionarse o maravillarse, la singularidad de su risa, su alegría de jugar...

Tres puntos de atención que permiten esbozar las principales referencias de un enfoque integral a la persona y a su sufrimiento: enfoque físico, social, emocional, psicológico y espiritual - visión global cuyas consecuencias pueden ser muy prácticas en los territorios y lugares "de lo negativo" que hemos mencionado.

Entre otras, se incluyen las siguientes consecuencias. Reconocer el habla y el lugar en la sociedad de aquel que se muere o que es golpeado por un accidente de vida. Salir de un marco demasiado rígido que se ha implantado con una medicina solamente técnica o tecnicista. Redefinir lo que es "lo bueno" para el paciente. Cambiar de legitimidad en las intervenciones de acompañamiento, que no estén basadas en el conocimiento y la racionalidad de los profesionales, sino en la escucha de la persona concernida en primer lugar, su deseo, el reconocimiento y el respeto hacia sus resistencias...

Por lo tanto, desde una visión centrada en el resultado, es decir, en el problema, vamos a una visión centrada en la persona en su complejidad y su unidad indisociables. No se trata tanto de curar, de reintegrar en la sociedad, o de encontrar trabajo o ingresos, o un alojamiento. Sino simplemente reintroducir la relación en un espacio en el que se le había puesto en pedazos y dispersado en lugares fragmentados.

\section{Un enfoque centrado en la persona}

El enfoque de los cuidados paliativos es una concepción del cuidado un poco sorprendente a primera vista: no se trata de curar. Paradoja. Esta es la formalización de una mirada hacia el cuidado que cuestiona radicalmente el sentido de la medicina tal como se ha desarrollado en el último siglo. El siglo XX ha revolucionado la medicina tradicional desarrollando de manera muy eficiente un enfoque científico y técnico al cuidado, donde se ha dado una gran importancia al profesional sanitario, a la tecnología, a las maquinas, a la química de la vida, al control de lo infinitamente pequeño, a la producción industrial de medicamentos, a la racionalización de los protocolos, etc. La medicina y el acompañamiento resultan de la encrucijada de muchas disciplinas científicas que se enriquecen constantemente de nuevos descubrimientos y desarrollos. Esta fuerte racionalización ofrece una ventaja innegable: que tiende a hacer posible un acompañamiento a muchos individuos. $\mathrm{La}$ estandarización del cuidado facilita su amplia difusión. No se olvide, esta medicina cura, sana, salva también un gran número de vidas.

Sin embargo, este enfoque científico y técnico presenta un riesgo nada despreciable: hacer que el humano se convierta en un objeto, que se va a tratar a escala industrial masiva y estandarizada, formateada. Uno de los escollos es, si nos centramos sobre el tratamiento de la enfermedad, deshumanizar la relación con la persona enferma. Y la persona en su totalidad desaparece, dividida en piezas separadas, disociadas, gestionadas por especialistas sucesivos. Desintegración que borra la unidad de su historia y hace más difícil su reintegración.

En oposición a este riesgo de cosificación y fragmentación, se han desarrollado a lo largo del siglo XX, como constelaciones, una multitud de otras visiones del 
cuidado que dibujan algo que se puede llamar una corriente humanista formada de varios enfoques muy heterogéneos y dispares, pero que tienen en común estar más " centrados sobre la persona ", para usar la bella expresión de Carl Rogers (2005). Esta orientación, que incluye la corriente de cuidados paliativos, podría caracterizarse por los siguientes rasgos principales: no se trata de resolver un problema, sino de acoger a una persona en lo que vive, y de mirar su singularidad no como un aislamiento, sino como un espacio de relación.

Acarrea para la persona que acompaña la adopción de actitudes concretas, como la atención a la conciencia, al deseo, a la libertad y a la decisión individual, valorizando la autonomía, el auto-conocimiento y el respeto, y tomando en consideración la interioridad.

A esta vasta corriente que atraviesa las profesiones de apoyo, de acompañamiento y de cuidado, también pueden estar asociados trabajos y reflexiones como aquellos que estén interesados por el concepto de "care" o el de "empowerment", donde la prioridad se da a las personas acompañadas, sus palabras, su participación en las decisiones que les afectan, así como su relación con el mundo y sus allegados...

No carece de interés darse cuenta de que este enfoque "humanista" afecta a la sociedad de manera extensa y transversal, en muchos lugares que la constituyen (escuelas, empresas, hospitales, asociaciones, instituciones sociales ...), tejiendo vínculos, resonancias y concordancias entre disciplinas diferentes que a menudo miramos como especialidades muy distintas: educación, cuidado, apoyo social, management, espiritualidad ... Entre muchos ejemplos posibles, solo evoquemos los tres siguientes : el notable desarrollo en los últimos veinte años del siglo XX de las asociaciones de pacientes que han hecho oír su voz y legitimado sus discursos frente a los profesionales, incluso en las instituciones hasta ahora muy centralizadas; la corriente más antigua de las nuevas pedagogías que podría resumirse en la hermosa fórmula de John Dewey: "Si quieres enseñar latín a John, tienes que saber un poco el latín y mucho de John"; el movimiento llamado de las "empresas liberadas" (Getz et al., 2013) $)^{5}$ donde la organización se emancipa de la jerarquía y el control.

Emerge entonces una visión global que permite romper las barreras y juntar iniciativas tan diversas como el desarrollo de los cuidados paliativos, el de la medicina humanitaria y de urgencia para las personas en situación precaria (por ejemplo, Médicos sin Fronteras o SAMU social en Francia), el de otros métodos de acompañamiento tales como el coaching, o de lo que ha sido llamado "artes terapias" y que abarca tantas prácticas posibles, y muchas otras formas de atención a la persona. Múltiples contribuciones, cada una desde territorios diferentes, para un cambio significativo de visión del acompañamiento y de concepción del cuidado: restituir al usuario su lugar de sujeto de lo que vive, y no de objeto tratado. Hacer accesibles los servicios de salud a los que están alejados, adaptados a los contextos y a las personas, sacar la decisión fuera de los lugares centralizados, dar la palabra y la iniciativa a las primeras personas involucradas: las que viven la situación particular de que se trate.

Frágiles espacios de reinserción de los que han sido borrados, de los que tan fácilmente podrían ser vistos como irrecuperables, incurables, indignos de la vida. 
Sin embargo, estos enfoques conllevan otros riesgos, especialmente el de una reivindicación para cada uno de su propia singularidad en un particularismo incondicional o en una propiedad intelectual, incluso como una verdad superior. Más allá de las buenas intenciones de principio, el gran reto para cada enfoque me parece que consiste en la interdisciplinariedad y la colaboración, concretamente organizadas entre las diversas personas involucradas: familiares, allegados, voluntarios, profesionales... Contribuir a la inteligencia colectiva es una prueba de fuego sobre el terreno, muy concreta, a menudo fatal. Apuntemos también que esta interdisciplinariedad es un punto clave del enfoque de los cuidados paliativos.

Ningún acompañamiento de la exclusión puede prescindir de ella.

\section{El ataúd de cristal}

El recorrido de Blanca Nieves es emblemático de toda trayectoria de exclusión. Expulsada de un reino donde inicialmente tenía su lugar propio, Blanca Nieves es violentamente excluida de su identidad original y esta condena amenaza su integridad, su vida. Pero entre esta vida de antes y la muerte a la que está destinada y enviada, hay un bosque. El bosque es el espacio de la exclusión por excelencia, zona intermedia entre una pertenencia social armoniosa, que se pierde, y el umbral de la muerte, que todavía no se cruzó. El bosque es el espacio de una triple pérdida: pérdida del sentido (es un lugar sin camino), pérdida del vínculo (es el espacio del aislamiento), y pérdida de la capacidad de subsistencia (espacio sin recursos, sin cultura y sin comida). El bosque es la calle, es la invisibilidad social, la "despertenencia", la deriva a los límites de la humanidad que precede a la muerte y que la produce.

Sin embargo, Blanca Nieves, en el bosque, sobrevive: se encuentra con esta extraña cosa llamada la casa de los enanos: una casa demasiado diminuta, donde vive una vida demasiado pequeña, sin ningún otro proyecto que la gestión de lo cotidiano. Allí sufre tres graves agresiones: la misma madrastra con cientos de rostros, que la había expulsado del espacio social, la persigue para destruirla hasta en el corazón de la exclusión. La asalta en su respiración, después en su cabeza, y luego en la garganta.

El cordón, primero, la deja sin respiro: perder la capacidad de recuperar el aliento, de dar un paso atrás, de descansar, de recobrar algo de libertad y paz, quedarse sin aire. Después, el peine, que envenena la cabeza: pierde la capacidad de pensar, de anticipar, controlar, decidir. Finalmente la manzana que cierra la garganta de Blanca Nieves en ambas direcciones: la de la comida, que ya no se traga, y la de la palabra que ya no sale. Ya no más apetito, no más ganas, no más sabor, no más víveres ya sean culturales o intelectuales o espirituales. Y sin más palabras, ya no más voz: nada más que decir, nadie para escuchar. Estrangulación total. La palabra latina angustia significa esta estrechez y constricción.

Estas tres violencias conducen a Blanca Nieves al ataúd de cristal. Ya no puede hacer nada, ni limpiar, ni fregar los platos, Blanca Nieves se ha vuelto inútil para los enanos que somos: es nuestra sociedad la que la encarrila a la vía muerta del fin de la vida. Ni viva ni muerta, está retenida en el ataúd de cristal de los "territorios de lo negativo", suspendida fuera del tiempo, fuera del vínculo, fuera del sentido. 
Sin embargo, la iniciativa del príncipe logra romper este proceso de lenta ejecución. Empujado ya el ataúd, Blanca Nieves recobra la palabra, el gusto, el sentido, reintegra el corazón de la vida.

Los cuidados paliativos: o interesarse por Blanca Nieves.

\section{El acompañamiento recíproco}

Los enanos acompañan a Blanca Nieves como pueden en su tiempo de fuera de la vida. La actitud de ellos es representativa de las fuerzas dominantes de la sociedad en el tratamiento de la exclusión, que se puede resumir así: "el que pueda fregar los platos, que se muestre útil. Y para el que ya no puede hacer nada, hagamos un gueto que le aísla". Ante la extrañeza radical de los fines de vida, todos estamos acostumbrados a reaccionar como enanos: ver en Blanca Nieves una humanidad que se va acabando, y organizar su no-lugar al margen, fuera de la sociedad de los activos-útiles.

Siempre se puede tratar de acompañar a Blancas Nieves hacia la rehabilitación. Tal vez algunas de ellas tendrán éxito. Eso no impide que la sociedad también pueda ser acompañada para reaprender a encontrar a los excluidos y para dar sentido a este encuentro. No sólo el sentido de una ayuda humanitaria unilateral dirigida a los que más sufren, y a los más desafortunados de los humanos. Sino al contrario, abrirse a lo que Blanca Nieves puede, también, enseñarnos a ver. Abrirse a lo que estos encuentros pueden enseñarnos: a encontrar que ya no sabemos encontrar, ni en el otro, ni en nosotros mismos.

Cuando nos acercamos al ataúd de cristal, tarde o temprano lo empujamos. Tendremos que conocer el malestar de afrontar la inercia, las resistencias feroces y los miedos muy profundos, empezando por los nuestros propios. Pronto surgirán los de la sociedad. Acompañar a cualquier forma de fin de vida es confrontar una parte de la sociedad a la realidad que no quiere ver y le aterroriza. A veces se tratará de desafiar a tal ayuntamiento que prohíbe la mendicidad en el centro de la ciudad, o elimina los bancos de las zonas turísticas, para hacer más invisible la precariedad. Otras veces se tratará de nombrar explícitamente tal decisión tomada por profesionales por conveniencia para consigo mismos y contribuyendo así más o menos directamente al desprecio de las personas destinatarias...

El acompañamiento es recíproco: cualquier persona que se considere perjudicada interpela al grupo que la pone en evidencia. Inevitablemente seremos percibidos como indeseables mensajeros portadores de su visibilidad y de su palabra. Acompañar a los más frágiles, también es acompañar a la sociedad que les pone al margen. A menudo tendremos que empezar por descubrir y encontrar este rechazo dentro de nosotros.

\section{Conclusiones}

Estoy personalmente convencido de que este trabajo exigente de reintegración de sí mismo, a veces dolorosa, es la única oportunidad de ser feliz profundamente. En la medida en que sabremos tomar el tiempo para encontrar, escuchar, darle su importancia a quien cuya miseria nos asusta, nos liberaremos poco a poco de la nuestra, y de nuestra estrechez personal y colectiva: nuestra angustia. El que acompañamos 
nos trabaja, nos esculpe, nos da nueva forma, nos compromete profundamente en el encuentro con nosotros mismos.

Por supuesto, este encuentro es inevitablemente despojante, áspero, brutal, desestabilizador y desconcertante. Por lo tanto, es imprudente aventurarse solo en esta cita capital donde uno puede perderse rápidamente. El encuentro con el Minotauro sólo es posible con el firme y estable apoyo de Ariadna, que permanece vinculada al que se aventura en lo más oscuro del laberinto. Debemos, también, estar vinculados, sostenidos, acompañados en esta íntima Odisea. Se trata de hacer posible el reencuentro con la propia intimidad, la propia profundidad, la propia interioridad. La interioridad no es un objeto, es un laberinto. El fondo de este laberinto es un Minotauro y también el enfrentamiento a ese Minotauro. Marchamos a su encuentro.

Descubrimos que la interioridad es primero una puerta cerrada, después un laberinto lleno de arena. Toneladas de arena a retirar con las manos, donde el desaliento es frecuente. A veces totalmente inevitable.

¿Cómo avanzar sin perderse? ¿Qué tipo de apoyo? Necesitamos tres cosas:

-un vínculo que legitima nuestra presencia y le da sentido, que puede ser una habilidad profesional, un conocimiento de herramientas y técnicas, una forma de compromiso con la apertura, la convicción de que este encuentro es una necesidad compartida.

-también tenemos una gran necesitad de escuelas de la relación, de la intimidad personal y profesional, de la interioridad. Es un mundo...

-y de ser uno mismo escuchado por personas suficientemente abiertas y sabias: una escucha nutrida, compleja, múltiple, que permita conocerse mejor a sí mismo y ser más abiertos a nuestras más profundas aspiraciones en la vida.

Blanca Nieves solo será despertada por los que se le acerquen y la empujen: se despierta fuera de ellos y se despierta dentro de ellos. El despertar de Blanca Nieves dentro de sí es una fiesta, no es ni un deber, ni un examen, ni una obligación moral. Acompañar al fin de vida es una oportunidad de madurez y de apertura apasionante. La oportunidad de convertirnos en nosotros mismos, como sugiere Gandhi en "el cambio que queremos ver."

\section{Bibliografía:}

EMMANUELLI X. (2009). Permanence de la fragilité. En Balmary M, Basset $\mathrm{L}$, Emmanuelli X, Vanier J et al. (eds). La fragilité, faiblesse ou richesse. Paris, Albin Michel.

GETZ I \& CARNEY BM. (2013). Liberté et Compagnie. Paris, Flammarion.

HEINICH N. (2012). De la visibilité, excellence et singularité en régime médiatique. Paris, NRF, Gallimard.

LEBLANC G. (2009). L'invisibilité sociale. Paris, Presses Universitaires de France. LHUILIER D. (2011). Souillure et transgression: le travail surle négatifpsychosocial. En Corteel D \& Le Lay S. (eds). Les travailleurs du déchet. Toulouse, Editions Erès, Col. Clinique du travail.

ROGERS C. (2005). Le développement de la personne (On Becoming a Person). Paris, Dunod. 


\section{Notas al pie}

1. Artista, coordinador de talleres en el ámbito de la salud, social y laboral. Crea en 2007 un taller acogiendo personas en situación de precariedad y sin techo. Coordina el taller de arteterapia en servicio de adictología / alcohología del hospital de Saint-Cloud (Paris) hasta 2014. Arteterapeuta docente y supervisor, enseña la práctica del acompañamiento en el Instituto de Formación Social, (Paris), y en el Máster de Arteterapia UPV (Valencia). Junto con María Montero-Ríos investiga desde el marco del arteterapia las posibilidades de los cuentos, como semillas que nutren la creatividad y la imaginación y permiten resonar desde una subjetividad compartida.

2. Esta noción de invisibilidad social fue desarrollada por el filósofo Guillaume Leblanc (2009).

3. Nathalie Heinich (2012) explora el surgimiento de elitismo mediático en el siglo XX que basa la excelencia sobre la única visibilidad.

4. No estoy hablando de las relaciones amorosas o emocionales: la relación que permite una expresión auténtica de lo que se vive, se siente o se actúa en cualquier situación personal o profesional, puede llamarse relación de intimidad. Puede ser experimentado en la relación individual con una persona acompañada. También puede vivirse en situaciones de relaciones grupales.

5. La edición original fue publicada bajo el título: Free your employees and let them lead your business ti higher productivity, Crown Business edition, NY 2009 